\title{
ADENOCARCINOMA OF DUODENUM AT THE DUODENOJEJUNAL FLEXURE
}

\author{
S.K. Sahu ${ }^{1 凶}$, P.K. Singh ${ }^{1}$, B.P. Singh ${ }^{1}$, S. Raghuvanshi ${ }^{2}$, P.K. Sachan ${ }^{1}$ \\ Himalayan Institute of Medical Sciences, Swami Ram Nagar, India \\ 1) Department of General Surgery \\ 2) Department of Radio-diagnosis
}

\begin{abstract}
ADENOCARCINOMA OF DUODENUM AT THE DUODENOJEJUNAL FLEXURE (Abstract): Adenocarcinoma of the duodenum is an exceedingly rare condition representing not more than $0.3 \%$ to $0.4 \%$ of all gastrointestinal tract cancers. Clinical presentation is usually due to partial or complete obstruction of the duodenum. Computed tomography scan has a high accuracy in detecting metastatic spread to stage the disease. CASE REPORT: A 60 year woman presented with chief complaints of persistent bilious projectile vomiting containing undigested food material and pain in the upper abdomen since 6 months. Upper gastrointestinal endoscopy up to $2^{\text {nd }}$ part of duodenum revealed no abnormality. Contrast enhanced computed tomography (CECT) scan of abdomen showed a dilated stomach and duodenal dilatation up to $4^{\text {th }}$ part along with a concentric growth seen in the fourth part of duodenum at the duodenojejunal flexure, and multiple retroperitoneal lymph-adenopathy. Exploratory laparotomy revealed a tumor of the duodenojejunal flexure with dilatation of all the parts of duodenum and stomach. The tumor was seen encasing the superior mesenteric vessels and aorta. A palliative gastro-jejunostomy was performed. Patient had an attack of acute myocardial infarction on post-operative day 6th and expired. Histopathology of the specimen confirmed adenocarcinoma of duodenum. CONCLUSIONS: Adenocarcinoma of duodenojejunal flexure is extremely rare and sometimes difficult to diagnose. Computed tomography scan has a high accuracy in detecting the disease and its metastatic spread to stage the disease. For unresectable tumors, palliative gastro-jejunostomy is the treatment of choice.
\end{abstract}

KEY WORDS: ADENOCARCINOMA; DUODENUM; DUODENOJEJUNAL FLEXURE; COMPUTED TOMOGRAPHY SCAN; GASTRO-JEJUNOSTOMY

SHORT TITLE: Adenocarcinoma of duodenojejunal flexure

HOW TO CITE: Sahu SK, Singh PK, Singh BP, Raghuvanshi S, Sachan PK. Adenocarcinoma of duodenum at the duodenojejunal flexure. Jurnalul de chirurgie (Iaşi). 2013; 9(3): 253-256. DOI: 10.7438/1584-9341-9-3-8.

\section{INTRODUCTION}

Adenocarcinoma of the duodenum is an exceedingly rare condition representing not more than $0.3 \%$ to $0.4 \%$ of all gastrointestinal tract cancers. Adenocarcinoma occurring at duodenojejunal flexure is extremely rare and sometimes difficult to diagnose. $[1,2]$

\section{CASE REPORT}

A 60 year female presented with chief complaints of persistent bilious projectile vomiting containing undigested food material and pain in the upper abdomen since 6 months. On examination the patient was dehydrated and having a poor nutrition built. General examination revealed pulse $100 / \mathrm{min}$ and blood pressure 90/60mm $\mathrm{Hg}$. Abdominal examination revealed visible peristalsis in the upper abdomen, moving from left to right and presence of succusion splash without any obvious mass palpable.

Routine haemogram showed haemoglobin $7.9 \mathrm{mg} / \mathrm{dL}$, total leukocyte

Received date: 18.01 .2013

Accepted date: 31.01 .2013

Correspondence to: Shantanu Kumar Sahu, MS, FAIS, FMAS, FIAGES; Associate Professor

Department of General Surgery, Himalayan Institute of Medical Sciences

Swami Ram Nagar Post - Doiwala Dehradun Uttarakhand, India, Pin 248140

Phone: 0091 (0) 9412933868

Fax: 0091 (0) 1352471317

E-mail: lntshantanu@yahoo.co.in 
count $4950 / \mathrm{mm}^{3}$ and differential leukocyte count showing neutrophil $74 \%$, lymphocyte $16 \%$, eosinophil $7 \%$, monocyte $3 \%$. Renal function tests and liver function tests showed normal values. Serum electrolytes showed $\mathrm{Na}^{+} 121 \mathrm{mEq} / \mathrm{L}, \mathrm{K}^{+} 3.1 \mathrm{mEq} / \mathrm{L}$ and $\mathrm{Cl}^{-} 90$ $\mathrm{mEq} / \mathrm{L}$. Serum albumin revealed $2.1 \mathrm{~g} / \mathrm{dL}$.

Upper gastrointestinal endoscopy up to $2^{\text {nd }}$ part of duodenum revealed no abnormality.
Contrast enhanced computed tomography (CECT) scan of abdomen was planned which showed a dilated stomach and duodenal dilatation up to $4^{\text {th }}$ part. A concentric growth was seen in the fourth part of duodenum at the duodenojejunal flexure, obstructing the lumen.

Multiple retroperitoneal lymphadenopathy and mild ascites was also detected (Fig. 1-3).

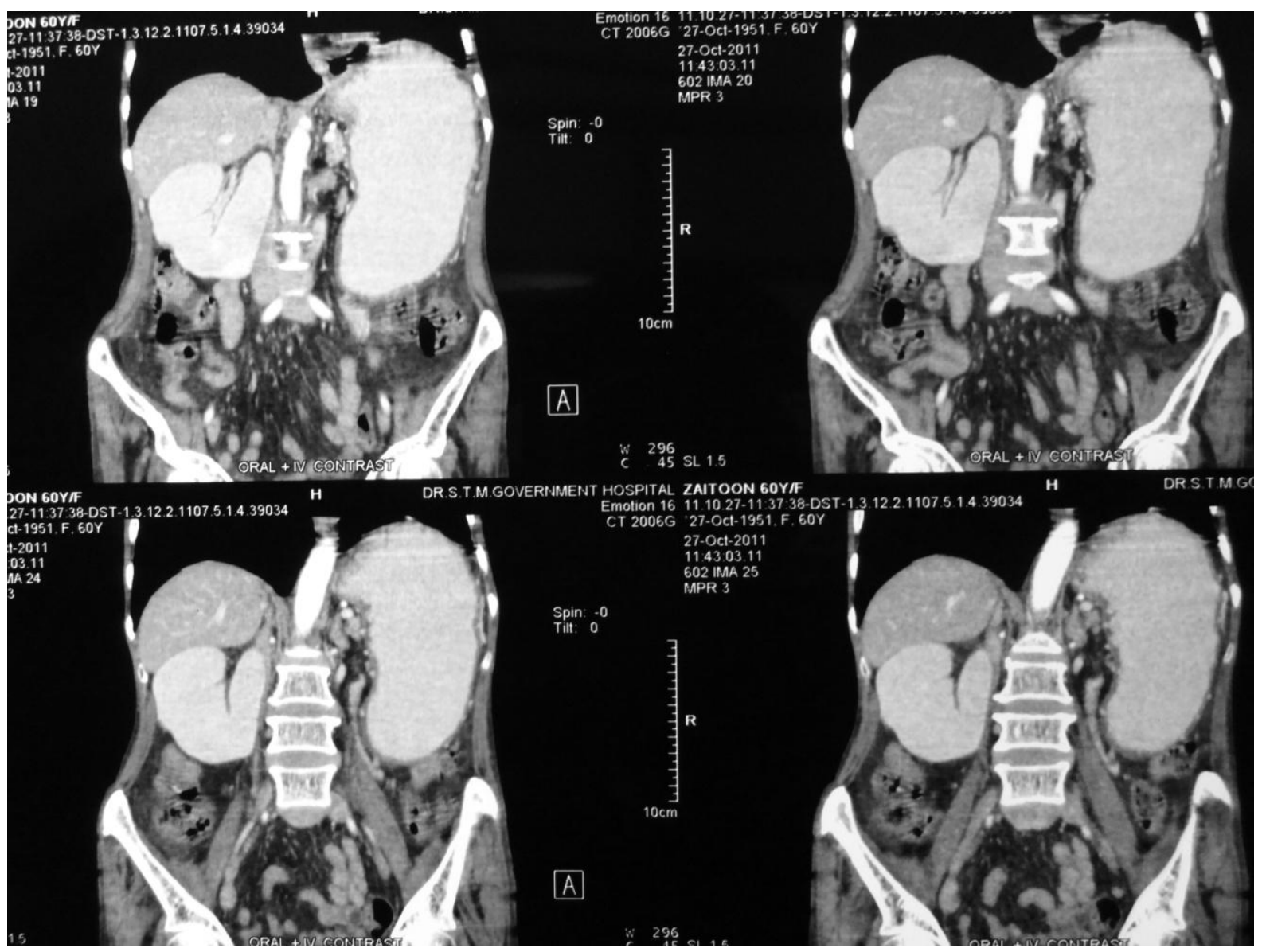

Fig. 1 CECT abdomen showing a dilated stomach and first, second, third and fourth part of duodenum

Exploratory laparotomy was planned after correction of the serum electrolytes which revealed a proliferative growth at the duodenojejunal flexure with dilatation of all the parts of duodenum and stomach. The growth was seen encasing the superior mesenteric vessels and aorta. Multiple paraaortic lymphadenopathies and mild ascites were also detected. Palliative gastrojejunostomy was done. Histopathology specimen was taken from the growth. Patient had an attack of acute myocardial infarction on post-operative day $6^{\text {th }}$ and expired.

Histopathology of the specimen confirmed adenocarcinoma of duodenum at the duodenojejunal flexure.

\section{DISCUSSION}

On reviewing the literature, although $45 \%$ of all carcinomas of the duodenum arise in the third and fourth portions of duodenum, the true incidence of adenocarcinoma of duodenum at the 
duodenojejunal flexure is still unknown. The age of presentation reported is usually in the $5^{\mathrm{t}}$ to $6^{\text {th }}$ decade of life and the mean duration of symptoms around 10 months [1-6].

Clinical presentation is usually due to partial or complete obstruction of the duodenum with persistent bilious vomiting and upper abdominal pain. Loss of weight and anemia with hemoccult-positive stools is frequent, although frank upper gastrointestinal tract hemorrhage is unusual $[3,5]$.

The diagnostic accuracy of duodenojejunal growth by barium studies is around 83\%. Upper gastro intestinal endoscopy has got a limited role in diagnosing the tumor as the procedure is usually terminated before reaching the site of the lesion. Enteroscopy by the "push" method using the pediatric colonoscope can yield a biopsy or a "sonde" enteroscopy can be used to view the lesion. Capsule endoscopy and double balloon enteroscopy (DBE) are the newer diagnostic modalities. Computed tomography scan has a high accuracy in detecting metastatic spread to stage the disease but has got a limited role in diagnosing primary tumor. $[3,6,7]$.

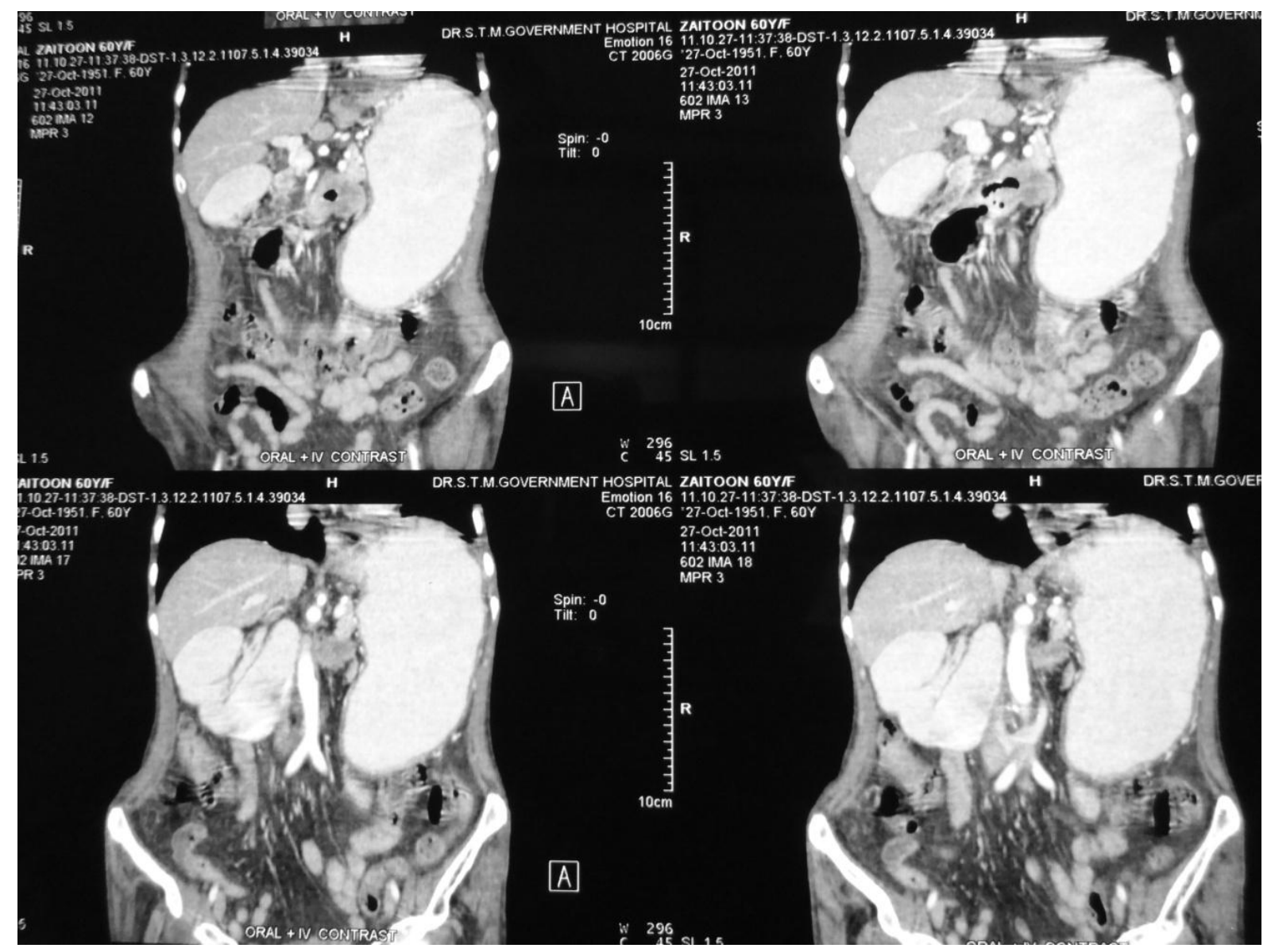

Fig. 2 CECT abdomen showing a concentric thickening of duodenum at duodenojejunal flexure

Duodenojejunal segmentectomy is the treatment of choice for duodenal angle of Treitz tumors with lymph node clearance. Assessment of tumor resectability, search for an adequate cancer-free proximal margin, and attainment of a tension-free anastomosis have been described as heavily hindered by the anatomy of the duodenum, which is embedded in the retroperitoneum and anteriorly bound by the superior mesenteric artery. Tumor diameter, histological grading, and invasion into the periduodenal tissues have been strongly suggested as the main factors affecting the outcome of these 
patients. Palliative gastro-jejunostomy is an ideal alternative for unresectable tumors $[3,6]$.

\section{CONCLUSIONS}

Adenocarcinoma

occurring at duodenojejunal flexure is extremely rare and sometimes difficult to diagnose.
Computed tomography scan has a high accuracy in detecting the disease and its metastatic spread to stage the disease.

For unresectable tumors, gastrojejunostomy is the treatment of choice.

\section{CONFLICT OF INTEREST}

None to declare

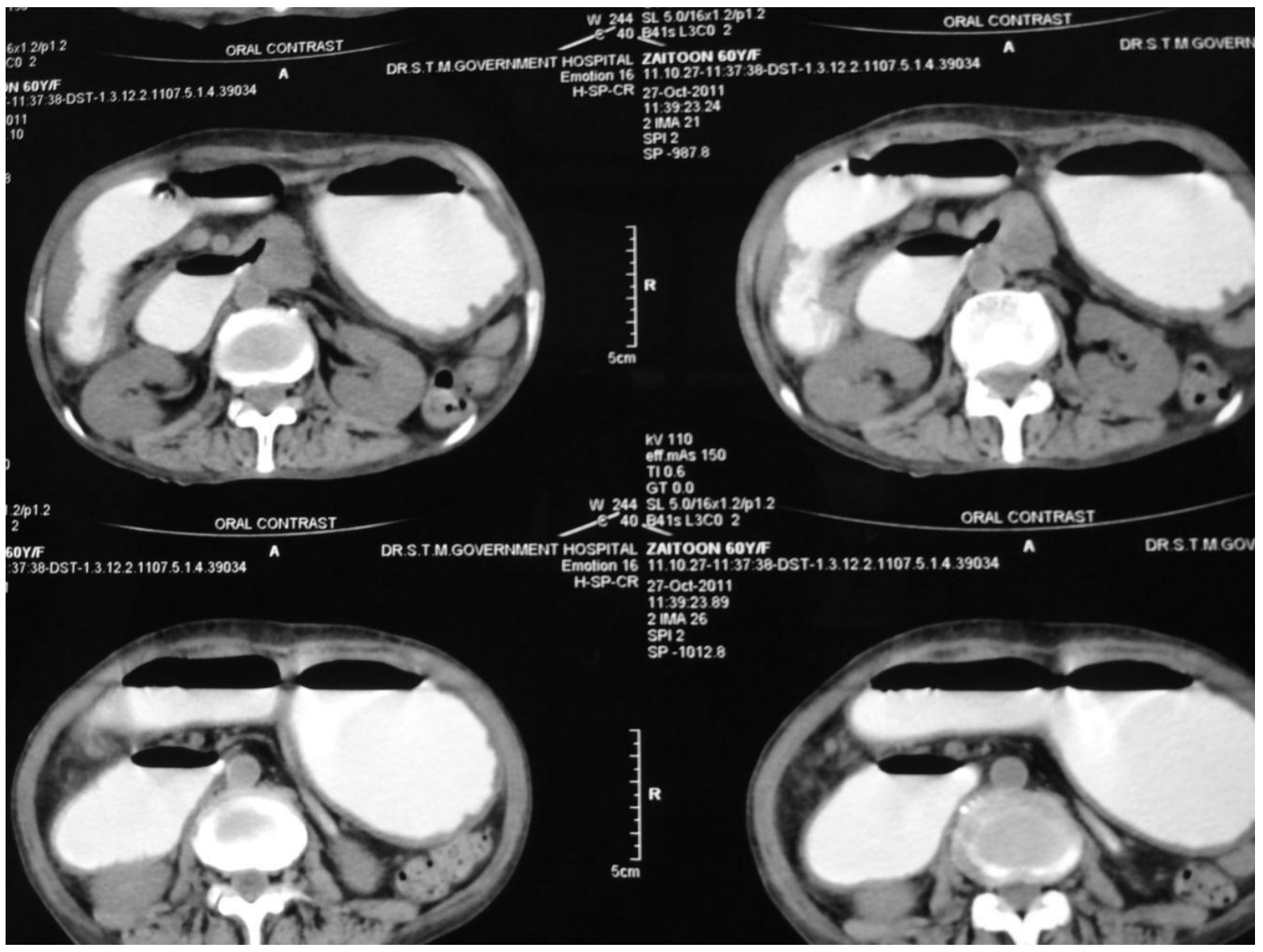

Fig. 3 CECT abdomen showing a concentric thickening of duodenum at duodenojejunal flexure

\section{REFERENCES}

1. Spira IA, Ghazi A, Wolff WI. Primary adenocarcinoma of the duodenum. Cancer. 1977; 39(4):1721-1726.

2. Sabiani P, Le Treut YP, Maillet B, et al. Les adenocarcinomes de l'angle duodeno-jejunal. J Chir (Paris). 1987; 124(1): 30-34.

3. Tocchi A, Mazzoni G, Puma F, et al. Adenocarcinoma the third and fourth portions of the duodenum: Results of surgical treatment. Arch Surg. 2003; 138(1): 80-85.

4. Fronticelli CM, Borghi F, Gattolin A, Ferrero A, Delsedime L. Primary adenocarcinoma of the angle of Treitz: case report. Arch Surg. 1996; 131(10):1109-1111.
5. Joesting DR, Beart RW, Van Heerden JA, Weiland LH. Improving survival in adenocarcinoma of the duodenum. Am J Surg. 1981; 141(2): 228-231.

6. Koli P, Dewoolkar VV, Butale U. Adenocarcinoma at angle of treitz: A report of two cases with review of literature. Indian $J$ Cancer. 2008; 45(4):179-181.

7. Yamamoto H, Kita H, Sunada K, et al. Clinical outcomes of double-balloon endoscopy for the diagnosis and treatment of small-intestinal diseases. Clin Gastroenterol Hepatol. 2004; 2(11): 1010-1016. 